\title{
Hedge-Algebras-Based Controller for Mechanisms of Relative Manipulation
}

\author{
Phan Bui Khoi and Nguyen Van Toan
}

Published online: 05 March 2018

(C) 2018 by KSPE and Springer

Int. J. Precis. Eng. Manuf., Vol. 19, No. 3, pp. 377-385, 2018

DOI: $10.1007 / \mathbf{s} 12541-018-0045-8$

The references 1, 4 and reference 5 of the above the article has been corrected as follows:

1. Khoi, P. B., "Calculation and Simulation of the Program Motion of Mechanisms of Relative Manipulation (MRM)," Journal of Science and Technology, Vol. 3, pp. 19-28, 2009.

4. Khoi, P. B., "Applying Principle of Compatibility for Analyzing Forces of Mechanism of Relative Manipulation Robot," Ph.D. Thesis, IMASH, RAS, 1997.

5. Khoi, P. B., "Dynamical Investigation of Relation Manipulation Mechanisms in Mechanical Processing," Proc. of National Conference on Mechanics, pp. 181-190, 2004.

The online version of the original can be found under doi:10.1007/s12541-018-0045-8

\#Corresponding Author: Nguyen Van Toan

Korea Institute of Science and Technology, Republic of Korea

E-mail: toan70411hd91@gmail.com 